\title{
Assessing Moroccan University Students' English Learning Motivation: A Comparative Study
}

\author{
Otmane Omari ${ }^{1 *}$, Mohammed Moubtassime ${ }^{2}$, Driss Ridouani ${ }^{3}$ \\ ${ }^{1}$ Department of English, Moulay Ismail University, Faculty of Letters and Humanities, Meknes, Morocco, \\ ${ }^{2}$ Department of English, Sidi Mohamed Ben Abdellah University, Faculty of Letters \& Humanities, Dhar El Mehraz, Fez, Morocco \\ ${ }^{3}$ Department of English, Moulay Ismail University, Faculty of Letters \& Humanities, Meknes, Morocco \\ Corresponding Author: otmaneomaari@gmail.com
}

\section{ARTICLE INFO}

Article history

Received: December 08, 2017

Accepted: January 21, 2018

Published: February 28, 2018

Volume: 9 Issue: 1

Advance access: January 2018

Conflicts of interest: None

Funding: None

Key words: Motivation, learning motivation, English, Moroccan

students, public university

\begin{abstract}
This study seeks to survey whether students are motivated to learn English or not and to evaluate the differences within and between three most known universities in Morocco, involving a private one, in terms of students' English learning motivation. Moreover, factors that make a student more motivated to learn English were investigated. This study examines motivation of university students according to their institution, gender, and other variables. Assessment of university students' motivation was by scores on items from the Academic Motivation Scale. The sample consisted of 329 undergraduate students from three different Moroccan universities. The most important finding was that participants in general are quite motivated to learn English with a score of $(\mathrm{M}=3.80)$ with regard to the overall score using a 5-point Likert scale, and a higher level of introjected extrinsic motivation $(\mathrm{M}=4.11)$, which means that they do such tasks because they are supposed or asked to do them. Moreover, factors such as how students consider university, their location during the academic year, and their decision behind choosing to go to university were found to affect students' motivation.
\end{abstract}

\section{INTRODUCTION}

For decades, students' low performance and lack of achievement has been a problem for many institutions. This may happen due to a lack of motivation and low beliefs in ones' abilities. Motivation for instance, has been the center of many studies dealing with students' psychology. More importantly, educational psychologists (e.g. Deci, Vallerand, Pelletier, \& Ryan, 1991; Dweck, Mangels, \& Good, 2004; Gardner, 1985; Pintrich \& Zusho, 2007; Vallerand, 2007) give more importance to studying the role of motivation in enhancing students' learning and achievement. Within language learning, motivation is considered as a key component for effective and successful language learning (Thompson \& Erdil-Moody, 2016). As demonstrated by Dörnyei (1998), motivation is referred to as an amount of energy that students have, which provides them with the needed directions. These directions lead to achievements and learning success. Motivation has been also assigned with goals. Students who are motivated to achieve a certain goal more likely believe in their abilities that they can fulfill their goal. In addition, evidence confirmed that goals and achievement goals demonstrate their usefulness in promoting students' motivation and beliefs in their abilities (Archer, 1994; Heyman \& Dweck, 1992).

With regard to motivation, no one can deny the fact that motivation is an important issue in the field of education, especially in higher education. However, many higher ed- ucation studies tend to focus on evaluating motivation of students within particular universities or within only one university. Moreover, only few researchers tackled the issue of students' academic motivation in Moroccan universities (especially within the department of English). Most studies that tackled Moroccan students investigated motivation of only high school students, as the case for Kyriacou and Benmansour (1997) and Smirkou (2015), or elementary school students such as the case for Wagner, Spratt, and Ezzaki (2008). For that reason, this study focuses on examining and comparing the differences between three Moroccan universities in terms of students' motivation to learn English and factors that make a student more motivated to learn English. This study seeks also to fill initial gaps in the literature by examining the academic motivation of university students in Morocco. Evaluating the differences in terms of motivation between public and private universities in Morocco will add to the literature that looks at this comparison. Moreover, nowadays there is a big shift to English mobile learning, and Moroccan university students demonstrated nowadays that they have positive attitudes toward English mobile learning (Omari, Bourekkadi, Slimani, Khoulji, \& Kerkeb, 2017). In fact, Studies on students' motivation will be of great use to language teachers and also to textbooks and mobile apps designers because they will be provided with research evidence. Meanwhile, this study intends to add more information to the literature by comparing students' English learning 
motivation of three best known universities in Morocco. In general, this study aims to answer the following research questions:

1) To what extent are students motivated to learn English in Moroccan universities?

2) Are there any differences in terms of motivation to learn English between public and private universities in Morocco?

3) What variables affect students' motivation?

To facilitate the analysis and the understanding of the findings in this study, the following section will explain the term 'motivation' in more details.

\section{MOTIVATION}

\section{Definition}

In recent studies, many researchers agreed that motivation is responsible for identifying one's behavior by supplying it with directions and energy (Dörnyei, 1998). Meanwhile, motivation in the literature is defined as a "process whereby goal-directed activity is instigated and sustained" (Pintrich \& Schunk, 1996, p. 4). However, Dörnyei (1998) noted that even though this definition is convincing, it stands at odds with what he called 'the traditional usage' of motivation. $\mathrm{He}$ explained that the traditional usage of motivation is commonly "understood as a fairly static mental or emotional state, or as a goal but not as a process" (118). On the other hand, he pointed out that motivation is "a process whereby a certain amount of instigation force arises, initiates action, and persists as long as no other force comes into play to weaken it and thereby terminate action, or until the planned outcome has been reached" (p. 118). In fact, Motivation has been defined by several authors and practitioners in the field of psychology; however, according to self-determination theory, motivation is composed of three different types: intrinsic motivation, extrinsic motivation and amotivation that should be defined separately (Deci \& Ryan, 1985).

\section{Intrinsic and extrinsic motivation}

Intrinsic motivation concept was used for the first time in a report by Harlow in 1950 (Deci \& Ryan, 1985). According to Sansone and Harackiewicz (2000), definitions of intrinsic motivation in the past led researchers to ask different questions and interpret the findings in different manners. For this reason, they insisted that the challenge for future researchers is to define the construct. For instance, Deci and Ryan (1985) put that intrinsic motivation is a source of energy to the human being. In another definition by Levesque (2012), he linked intrinsic motivation to interest in a task or activity. Interest, according to him, motivates learners and makes them eager and willing to participate in a particular activity or task. Similarly, intrinsic motivation was referred to as "doing something because it is inherently interesting or enjoyable” (Ryan \& Deci, 2000a, p. 55). In other words, activities that motivate the person intrinsically are the ones identified by enjoyment (Deci \& Ryan, 1985). Elsewhere, it was pointed out that the frequently used definition of intrinsic motivation includes doing an activity for the sake of doing it and not as a means to an end (Hidi, 2000).

On the other hand, extrinsic motivation is somewhat the opposite of intrinsic motivation even though they may interact in some cases. According to Deci and Ryan (1985), extrinsic motivation refers to the behavior of doing something where the reason for doing it is other than being interested in the task itself. They explained that extrinsically motivated behaviors differ from other behaviors by being determined either by controls or choices derived from the desires and values of the person. Hence, an activity that is extrinsically motivating can be the one completely motivating due to a desire to attain an outcome goal (Sansone \& Smith, 2000). Similar to that, Ryan and Deci (2000a) and Hidi (2000) defined extrinsic motivation as doing something because it will drive the person to a separable outcome or consequence. This is to say that extrinsic motivation differs from intrinsic motivation; the first is a means to an end, whereas the second is not. Furthermore, other researchers supported the idea that extrinsic motivation involves external motivating factors that depend upon success or failure such as: recognition or financial gain (Levesque, 2012), rewards or punishments (Lin, Mckeachie, \& Kim, 2003), and earning or avoiding something out of the self (Walker, Greene, \& Mansell, 2006). On the other hand, Sansone and Harackiewicz (2000) demonstrated that there are two main and emerging definitions of extrinsic motivation: extrinsic motivation is (a) a motivation that is built upon something external to the task and (b) a motivation that is built upon something external to the self.

According to Self Determination Theory (SDT), there are four types of extrinsic motivation: External regulation, Introjected regulation, Identified regulation, and Integrated regulation (Deci \& Ryan, 1985; Ryan \& Deci, 2000a). The first one symbolizes the least autonomous form of extrinsic motivation and it is the one contrasted with intrinsic motivation (Ryan \& Deci, 2000a). External regulation refers to the behavior of doing something for the sake of an external factor such as a reward or a fear of punishment (Deci et al., 1991). In the second type of external motivation -introjected regulation- the individual performs a task because of a self-imposed pressure such as anxiety or feelings of guilt (Vallerand, 2007). Put differently, introjected regulation represents actions performed by individuals with a feeling of pressure to stay away from anxiety or guilt, or to retain and reinforce self-esteem or self-worth (Ryan \& Deci, 2000a). These first two types of extrinsic motivation are linked to controlled motivation because they are both "associated with an external perceived locus of causality, sense of pressure, and perceived obligation" (Reeve, 2012, p. 155). The next two types of external motivation are linked to autonomous motivation. This is because they make students get a sense or a feeling of choice (Deci et al., 1991; Vallerand, 2007). Identified regulation refers to the act of identifying a regulation as being useful and important to the individual. For instance, self-regulating one's learning because the learner believes that this act is important for him/her to succeed. Integrated regulation represents a preferred choice to do such act because of its coherent with other features of the self (Val- 
lerand, 2007). In other words, integrated regulation occurs when one identified his/her choice of doing something as a need to get something else.

\section{Amotivation}

The concept of amotivation was first proposed by Deci and Ryan in 1985 as a third type of motivation in order to understand the human behavior (Vallerand et al., 1992). However, few researchers dealt with that concept as a measure of motivation in the past because the focus was more on studying the differences between intrinsic and extrinsic motivation (Baker, 2004). According to Deci and Ryan (1985), amotivation is related to helplessness. The authors added that this concept may go jointly with listlessness, self-disparagement, and depression. Furthermore, amotivation is conceptualized as a state of lack of probability between one's actions and outcomes (Barkoukis, Tsorbatzoudis, Grouios, \& Sideridis, 2008). In other words, amotivation is an act of lacking intention because the learner feels incompetent, belittles a task or believes that the task will not result in a wanted outcome (Ryan \& Deci, 2000a). This type of motivation, as claimed by Deci and Ryan (1985), occurs while failing frequently, believing that a desired outcome is inconceivable, or while receiving a negative feedback.

With regard to feedback, a study in 1984 by Baggiano and Barrett (as cited in Deci \& Ryan, 1985) demonstrated that negative feedback symbolizes a challenge for intrinsically motivated learners and increases their intrinsic motivation for the task; whereas negative feedback increases the feeling of incompetence for extrinsically motivated learners resulting in a state of amotivation. Eventually, Deci and Ryan (1985) added that extrinsically motivated learners are more likely to face the harm of amotivation while receiving a negative feedback. They claimed that a feedback which "leads to perceptions and feelings of incompetence, will diminish intrinsic motivation and perhaps lead to amotivation for that activity" (318).

\section{University Students Motivation}

Recently, university students' motivation to learn English has been the center of many studies. For instance, Bektaş-Çetinkaya and Oruç (2010) explored whether Turkish university students are motivated to learn English or not and their reason behind learning English. The study also investigated the differences between public and private university students in terms of English learning motivation. The findings of this study revealed that Turkish university students are quite motivated and that private university students' level of motivation is higher than public university students. Moreover, the desire to find a well-paying job was the main motivation to learn English for both, public and private university students. Besides, it is important to highlight that this study discussed students' motivation to learn English based on Gardner's socio-educational model which distinguishes between integrative motivation (one's desire to integrate into the international society) and instrumental motivation (one's desire to invest in the market, such as finding a job).

Meanwhile, in another recent study, Ngo, Spooner-Lane, and Mergler (2017) investigated types of motivation to learn English of Vietnamese' university English majors and non-majors. Unlike the previous study, this one was based on self-determination theory. The study revealed that both groups are extrinsically motivated to learn English and they study English to get some instrumental benefits. Meanwhile, English majors in this study were found more intrinsically motivated and experience less amotivation than non-English majors. This finding shows that studying English as a major motivates students more than studying it as part of a program. This, as suggested by the authors, may be due to an autonomous psychological and cognitive preparation to study English as a major. The authors also pointed out that Vietnamese' students sit and pass an entrance exam in order to be accepted in an English major program. However, its influence on students' learning motivation was not discussed.

Concerning factors affecting English learning motivation, Nawaz, Amin, and Tatla (2015) conducted a mixed methods study on that issue. The quantitative data revealed that students' motivation to learn English can be affected by their anxiety, interest in English, linguistic self-confidence, teacher and family influence, instrumentality, and integrativeness. These findings were endorsed by the qualitative data which also revealed other factors such as globalization, English being the language of international organizations, science, technology, media, and the status of English as an official language in the country. Similar to that, Rifai (2010) found that teachers and class course affect positively students' English learning motivation. In addition, instrumental motivation and integrative motivation toward learning English were very positive.

\section{METHODOLOGY}

\section{Participants}

Participants of this study consisted of 329 undergraduate university students. The method used in this study is a quantitative method where data were collected using questionnaires, which were completed anonymously by the participants. Data collection via questionnaires was conducted in April 2016 in three different Moroccan universities: Moulay Ismail University (MIU), Sidi Mohammed Ben Abdellah University (SMBAU), and Al Akhawayn University (AUI). It is also important to mention that about $58 \%$ of participants were females, and $42 \%$ were males, which was expected because most males did not accept to participate. Besides, it is worth mentioning that for Moroccan public universities, students are not required to sit and pass any entrance exam to be accepted in an English major program which is not the case for Al Akhawayn University. The latter is a private university requiring an entrance exam that involves English and other subjects in order to be accepted.

In this study, a Demographic Information Form was used to gather students' demographic information such as gender, age, university, class, institution, and location during the academic year. Other aspects were also added to the demographic information form. Those aspects were specially designed for that study in order to assess students' decision behind choosing to go to university. 


\section{Instrumentation}

In the current study, measures from the field of educational psychology were used to assess students' motivation. Quantitative analysis techniques were employed to answer the research questions. Meanwhile, because the aim of this study was to collect specific descriptive information about students' academic motivation, a questionnaire instrument was used. The language of the questionnaire was English and it was distributed to students from the department of English in all universities except for AUI because there is no Department of English their and the language of instruction in that institution is English. The same questionnaire was distributed to students of the three universities in the mid of the second semester of the Academic Year.

Assessment of university students' motivation was by scores on items from the Academic Motivation Scale (AMS) adapted from Vallerand et al. (1992). The scale is consisted of 28 items that are divided into 7 subscales. The items measure students' intrinsic motivation [to know, toward accomplishment, and to experience stimulation], extrinsic motivation [identified, introjected, and external regulation], and amotivation. Students were asked to answer the following question "Why do you go to university to study English?" by indicating how much they agree or disagree with each statement. Sample items that measured students' motivation included 'I go to university to study English because I experience pleasure and satisfaction while learning new things', 'because eventually it will enable me to enter the job market in a field that I like', and 'honestly I don't know; I really feel that I am wasting my time at university studying English'. The ratings of the previous item were reversed before calculating the scores as it is negatively worded. Students valued themselves on a five-point Likert type scale. In terms of Cronbach alpha, Vallerand et al. (1992) obtained a Cronbach's $\alpha$ coefficient of 0.81 . Cronbach's $\alpha$ coefficient for the current study was 0.80 .

\section{RESULTS}

\section{Descriptive results}

In terms of participants' demographic information, Figure 1 displays a general view of the study's sample by gender and according to their institutions. The highest number of participants were females from SMBAU (80 participants, representing $24.32 \%$ of the total $\mathrm{N}=329$ ). The other participants were as follows: 47 males (14.29\%) from SMBAU, 59 females $(17.93 \%)$ and 45 males $(13.68 \%)$ from MIU, 53 females $(16.11 \%)$ and 45 males $(13.68 \%)$ from AUI.

Descriptive statistics for students' decision behind choosing to go to university were included in this study. Items data of this question were based on respondents (cases) because it was a multiple response question and participants were allowed to select more than one answer. The results displayed that interest in the subject (about 49\%) and the desire to achieve a higher degree (about 41\%) were the most important reasons behind students' decision to go to university. Meanwhile, $16 \%$ of the participants reported that university was their only choice. More specifically, $65 \%$ of respondents within MIU reported that they decided to go to university because they were interested in the subject, and $27 \%$ because of their willingness to get a higher degree. Similar to that, $51 \%$ of students within SMBAU reported that interest was the reason behind their decision, followed by the desire to get a higher degree (37\%). Concerning students within AUI, $60 \%$ of the respondents declared that their aim behind going to university was to get a higher degree. However, only $28 \%$ within the same university said that interest was the reason behind their choice, $10 \%$ reported that a family member or a teacher advised them, and $11 \%$ said that it was their only choice. On the other hand, the highest percentage of students who confirmed that their decision behind going to university was their only choice were students of MIU ( $22 \%$ within their university) followed by participants from SMBAU (15\% within SMBAU).

Concerning students' motivation, the AMS in the current study was made up of 28 items assessing students' intrinsic, extrinsic, and amotivation as mentioned earlier. The overall score of motivation scale revealed that students in general display a level of motivation that is a bit higher than average. Motivation mean within the three universities was 3.80 , which falls near to the agreement that the individual is motivated toward learning. SMBAU students score $(\mathrm{M}=3.83)$ was somewhat equal to that of AUI students $(\mathrm{M}=3.82)$ and higher than the score of MIU students $(\mathrm{M}=3.74)$.

Students' highest score within all the items was that representing extrinsic introjected motivation $(\mathrm{M}=4.11)$. The second highest score was the one representing intrinsic motivation to know $(\mathrm{M}=3.88)$. On the other hand, students rated their amotivation as low and demonstrated a total score of $\mathrm{M}=$ 2.03. The lowest score of amotivation was within SMBAU students $(M=1.91)$. Meanwhile, the other items varied from a mean of 3.40 to 4.11 . Besides, due to the fact that there is more than one type of motivation, a score of each type of motivation was computed individually to measure students' orientations. In particular, the mean of intrinsic motivation items $(\mathrm{M}=$ $3.72)$, extrinsic motivation items $(M=3.87)$, and amotiva-tion $(M=2.04)$ were calculated separately. Figure 2 demonstrates the means' difference between the three universities. As present-ed in Figure 2, not much differences were displayed between students intrinsic and extrinsic motivation except the case of MIU students' intrinsic motivation which was less than the others $(M=3.63)$. Additionally, SM BAU students were found somewhat extrinsically motivated $(\mathrm{M}=3.93)$ more than $\mathrm{MIU}$ students $(\mathrm{M}=3.85)$ and AUI students $(\mathrm{M}=3.83)$. Concerning amotivation, SMBAU students rated themselves as having a low degree of amotivation $(\mathrm{M}=1.91)$

In terms of gender, females within the three universities showed higher intrinsic $(\mathrm{M}=3.76)$ and extrinsic motivation $(\mathrm{M}=3.97)$ than males (respectively $\mathrm{M}=3.69 ; \mathrm{M}=3.77$ ). Moreover, females within the three universities displayed low scores of amotivation ( $\mathrm{M}=1.96)$ except the case of MIU where females demonstrated a higher degree of amotivation $(\mathrm{M}=2.15)$ than males $(\mathrm{M}=1.98)$.

Meanwhile, all participants who declared that they live with their parents during the academic year revealed a higher degree of intrinsic $(\mathrm{M}=3.80)$ and extrinsic motivation $(\mathrm{M}=3.97)$ and a lower degree of amotivation $(\mathrm{M}=1.90)$ unlike those who live alone (respectively $\mathrm{M}=3.72, \mathrm{M}=$ $3.79, \mathrm{M}=2.10$ ) or in a shared house (respectively $\mathrm{M}=3.69$, 
$\mathrm{M}=3.82, \mathrm{M}=2.13)$. Besides, students who decided to go to university because it was their only choice showed less amount of intrinsic and extrinsic motivation, and higher amount of amotivation unlike the others as demonstrated in Table 1. On the other hand, participants who chose to go to university because of interest or to achieve a higher degree displayed a higher degree of intrinsic and extrinsic motivation, and a lower degree of amotivation than the others.

Furthermore, a correlation test was performed to test the relationships between AMS subscales (intrinsic, extrinsic, and amotivation). Intrinsic motivation was found positively correlated with extrinsic motivation $r=.643, \mathrm{p}<.001$. However, amotivation was found negatively correlated with the other sub-scales of motivation. The most important negative correlation was found between amotivation and intrinsic motivation $(r=-0.497, p<0.001)$. Similar to that, there was a negative correlation between amotivation and extrinsic motivation $(\mathrm{r}=-0.488, \mathrm{p}<0.001)$.

\section{Summary of findings}

Within the AMS, students from SMBAU and AUI demonstrated a score of motivation slightly higher than students from MIU. According to the findings, students' overall motivation did not exceed the average. Meanwhile, extrinsic introjected

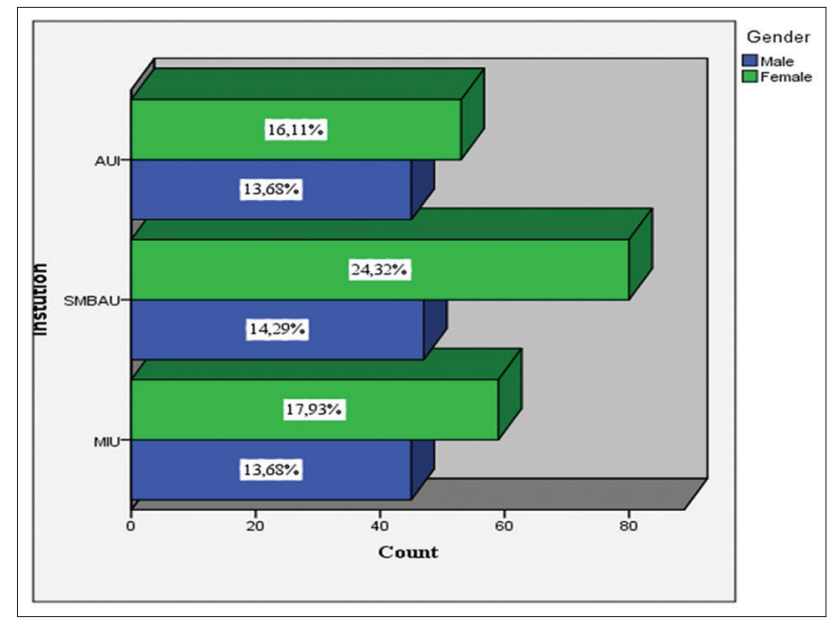

Figure 1. Participants according to their gender and institution motivation was found the highest rated orientation of students within the three universities. Similar to that, intrinsic motivation to know was found the second highest orientation of all participants. In other words, students within the three universities demonstrated a higher extrinsic orientation than the intrinsic one. More importantly, they rated themselves low in experiencing amotivation. Students from SMBAU displayed higher extrinsic motivation than the others, and were the lowest participants to experience amotivation in comparison with MIU participants who declared that they experience amotivation more than students of the other universities (SMBAU and AUI). Moreover, MIU students were found less intrinsically oriented than the others. Concerning gender, females again were found more extrinsically and intrinsically motivated and experience less amotivation than males, except the case of MIU students where females experience higher amotivation than males. Besides, all students who declared that they decided to go to university because it was their only choice displayed lower degrees of extrinsic and intrinsic motivation and higher degrees of amotivation than the others.

\section{DISCUSSION}

The primary aim of this study was to measure students' English learning motivation and factors that make a student

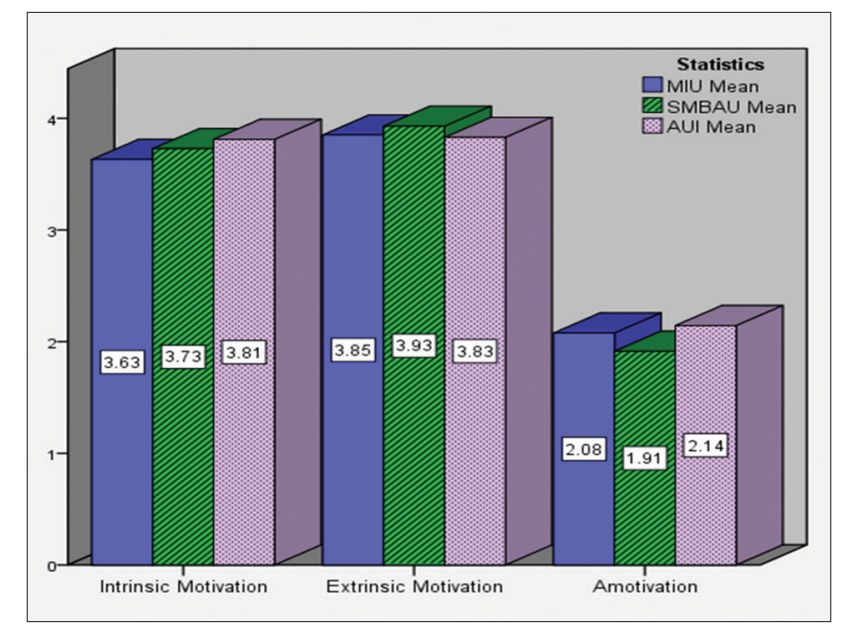

Figure 2. Means of intrinsic, extrinsic and amotivation within each university

Table 1: Participants' means of motivation according to their reason behind going to university

\begin{tabular}{|c|c|c|c|c|c|c|}
\hline & & $\begin{array}{c}\text { Intrinsic } \\
\text { motivation }\end{array}$ & $\begin{array}{c}\text { Extrinsic } \\
\text { motivation }\end{array}$ & Amotivation & $\mathbf{N}$ & $\begin{array}{c}\text { Motivation } \\
\text { means (total) }\end{array}$ \\
\hline \multirow{6}{*}{$\begin{array}{l}\text { Why did you decide to } \\
\text { go to university? a }\end{array}$} & Interested in the subject & 4.02 & 3.93 & 1.54 & 161 & 3.98 \\
\hline & $\begin{array}{l}\text { Advised by a teacher or a } \\
\text { family member }\end{array}$ & 3.80 & 3.99 & 2.01 & 23 & 3.89 \\
\hline & $\begin{array}{l}\text { To achieve a higher } \\
\text { degree }\end{array}$ & 3.86 & 4.00 & 1.60 & 134 & 3.93 \\
\hline & It was the only choice & 3.13 & 3.57 & 2.85 & 54 & 3.35 \\
\hline & None of the above & 3.79 & 3.87 & 2.22 & 8 & 3.83 \\
\hline & Total & 3.72 & 3.87 & 2.04 & 380 & 3.80 \\
\hline
\end{tabular}

Note. $\mathrm{N}$ total is based on respondents. ${ }^{\text {a }}$ Dichotomy group tabulated at value 1 
more motivated to learn English. Particularly, the aim was to assess the difference between MIU, SMBAU, and AUI students' in terms of their motivation. Regarding the overall score of students' motivation, the results confirmed that students within the three universities display a medium level of motivation.

Students' ratings of their overall motivation demonstrated that they are quite motivated toward learning. However, types of motivation differ and cannot mean the same thing. In the current study, AUI and SMBAU students were found more motivated than MIU students. These findings demonstrate that there are no differences in terms of English learning motivation between students who pass an entrance exam before being accepted and those who do not take any entrance exam to study English as their major. Thus, we can conclude that motivation to learn English is neither a matter of studying it in a public or a private university nor in a university that requires an entrance exam or the one which does not require an entrance exam. The current study finding contradict Bektaş-Çetinkaya and Oruç (2010) finding that private university students are more motivated to learn English. Meanwhile, results of AUI and SMBAU are similar to those of Ngo et al. (2017) confirming that there is no difference in terms of English learning motivation between Non-English majors (AUI students in this study) and English-majors (SMBAU in this study).

Besides, most students from the three universities showed higher introjected extrinsic motivation. This type is a state of motivation resulting from feelings of pressure (Ryan \& Deci, 2000b). Students within that category are known to be guided and motivated by force and not by choice (Deci et al., 1991). This means that they do such tasks because they are supposed or asked to do them. Meanwhile, students' high extrinsic orientation explains that they tackle learning as a means to an end. This is to say that their motivation is directed more to learning at university in order to get a reward or a job rather than gaining knowledge or developing their skills. This finding is similar to the findings of other studies (Bektaş-Çetinkaya \& Oruç, 2010; Engin, 2009; Ngo et al., 2017; Rifai, 2010) that students' motivation to learn English is related to instrumental benefits' desire.

On the other hand, the positive result in this study was that of students' amotivation. The overall results revealed that students do not experience amotivation much, which is conceptualized as the state of lacking intention to learn and to do schoolwork. This state of amotivation could make students stop participating in academic activities because they feel undeceived and disappointed (Vallerand et al., 1992). Besides, the only ones who declared a high sense of amotivation were students who stated that they decided to go to university because it was their only choice. These results were highly expected. This is to say that students who regard university as unimportant will not be much motivated as those who consider university as a source of interest, enjoyment, or also as a means to an end.

Meanwhile, intrinsic and extrinsic orientations within the three universities were found highly correlated. This means that when students' intrinsic motivation is high, also their extrinsic motivation is high. This finding is consistent with prior research which revealed that both motivation orientations (intrinsic and extrinsic) can coexist (Dev, 1997; Park, 2011). Nevertheless, students' academic achievement, which was not assessed in this study, is linked to intrinsic oriented students because those students can easily overcome failures more than extrinsic oriented ones. On the other hand, amotivation was found negatively correlated with all the other sub-scales. More than that, the strongest negative correlation was found between amotivation and intrinsic motivation. By evidence, amotivation should have a negative correlation with the other AMS sub-scales, and the strongest negative correlations should be with intrinsic motivation (Alivernini \& Lucidi, 2008). This means that the more intrinsically oriented students are, the less sense of amotivation they may experience. Therefore, it is important to focus more on ways to develop students' intrinsic motivation in higher education.

Concerning gender, females from AUI and SMBAU in the current study experienced less amotivation, and were found more intrinsically and extrinsically motivated. This may be due to the fact that most females are interested in the subjects they are studying more than males and they consider university as a source of knowledge. Besides, this study revealed also that students who live with their parents during the academic year were found more intrinsically and extrinsically oriented than those who live alone or in a shared house. We can say that this difference could be due to the kind of support students receive from their parents. For instance, students who live with their parents may receive daily verbal persuasion that enhances their motivation more than those who live alone or in a shared house.

\section{CONCLUSION}

To sum up, this study indicated the degree of English learning motivation of MIU, SMBAU, and AUI students. It also revealed variables that may affect students' motivation and make a student more motivated to learn English than the others. In general, most participants were found having an average amount of motivation. That is, students' motivation does not depend on whether they are studying in a private or a public university. On the other hand, this study was able to demonstrate the difference between males and females in terms of their motivation according to the university to which they belong. Females were found in general more motivated than males. Other factors such as how students consider university, their location during the academic year, and previous decision behind choosing to go to university were found to affect students' motivation. All in all, this study revealed that in order to enhance students' motivation, which will of course affect positively their performance and outcome achievement, focus in the future should be directed toward students' self-regulation strategies, self-regulated learning, anxiety avoidance, interest and intrinsic motivation.

\section{LIMITATIONS}

Despite the fact that the research has reached its aim, the findings of this study may be limited to a population similar to undergraduate students from MIU, SMBAU, and AUI. 
Because of the research nature, this study was limited to undergraduate students enrolled in the department of English (MIU and SMBAU) and others who mastered English (AUI) with the aim of assessing their English learning motivation and factors affecting it. Meanwhile, data collected for this study was collected during the middle of the second semester and it was limited to 329 participants (total of accepted questionnaires) due to the fact that it was difficult to convince more students to participate. For that reason, the results may be generalized to only students within the same universities and during the same semester. It should be also noted that this study was limited to quantitative data collection. It is also important to mention that the current study was limited in terms of the literature review to prior research studies on motivation outside Morocco. This was due to the lack of Moroccan case studies concerning university students' motivation to learn English.

\section{IMPLICATIONS}

Motivation in this study gives a clear description concerning students' orientations. The study shows that most students within the three universities are extrinsically oriented. This description of students' orientation will help professors and other people interested in the domain of higher education to generate an idea concerning students' thinking. More than that, it will also facilitate things for them and make clear the techniques that should be used to motivate students. On the other hand, the correlations generated between the AMS subscales provide professors in particular with the important relationships that are linked together. Those correlations give a reliable understanding on why some students are more motivated, and perform better than others. In general, the findings of this study within the framework presented in the literature will surely help enhancing students' performance and outcomes, which will also contribute to the development of the Moroccan university.

\section{ACKNOWLEDGEMENTS}

The authors are very grateful to all students who accepted to participate in this study. Their willingness to give their time so generously has been very much appreciated.

\section{REFERENCES}

Alivernini, F., \& Lucidi, F. (2008). The Academic Motivation Scale (AMS): Factorial structure, invariance and validity in the Italian context. Testing, Psychometrics, Methodology in Applied Psychology, 15(4), 211-220.

Archer, J. (1994). Achievement Goals as a Measure of Motivation in University Students. Contemporary Educational Psychology, 19(4), 430-446. http://dx.doi. org/10.1006/ceps.1994.1031

Baker, S. (2004). Intrinsic, extrinsic, and amotivational orientations: Their role in university adjustment, stress, well-being, and subsequent academic performance. Current Psychology, 23(3), 189-202. http://dx.doi. org/10.1007/s12144-004-1019-9
Barkoukis, V., Tsorbatzoudis, H., Grouios, G., \& Sideridis, G. (2008). The assessment of intrinsic and extrinsic motivation and amotivation: Validity and reliability of the Greek version of the Academic Motivation Scale. Assessment in Education: Principles, Policy \& Practice, 15(1), 39-55. http://dx.doi.org/10.1080/09695940701876128

Bektaş-Çetinkaya, Y., \& Oruç, N. (2010). Turkish students“ motivation to learn English at public and private universities. Procedia - Social and Behavioral Sciences, 2(2), 4662-4666. http://dx.doi.org/10.1016/j.sbspro.2010.03.746

Deci, E. L., \& Ryan, R. M. (1985). Intrinsic Motivation and Self-Determination in Human Behavior. New York: Plenum. http://dx.doi.org/10.1007/978-1-4899-2271-7

Deci, E. L., Vallerand, R. J., Pelletier, L. G., \& Ryan, R. M. (1991). Motivation and Education: The Self-Determination Perspective. Educational Psychologist, 26(3-4), 325-346. http://dx.doi.org/10.1080/00461520.1991.965 3137

Dev, P. C. (1997). Intrinsic Motivation and Academic Achievement: What Does Their Relationship Imply for the Classroom Teacher? Remedial and Special Education, 18(1), 12-19. http://dx.doi.org/10.1177/074193259701800104

Dörnyei, Z. (1998). Motivation in second and foreign language learning. Language Teaching, 31(03), 117-135. http://dx.doi.org/10.1017/S026144480001315X

Dweck, C. S., Mangels, J. A., \& Good, C. (2004). Motivational Effects on Attention, Cognition, and Performance. In D. Y. Dai \& R. J. Strnberg (Eds.), Motivation, Emotion, and Cognition: Integrative Perspectives on Intellectual Functioning and Development (pp. 41-55). Mahwah, NJ: Lawrence Erlbaum Associates Publishers.

Engin, A. O. (2009). Second language learning success and motivation. Social Behavior and Personality: an international journal, 37(8), 1035-1041. http://dx.doi. org/10.2224/sbp.2009.37.8.1035

Gardner, R. C. (1985). Social psychology and second language learning: The role of attitudes and motivation: Arnold.

Heyman, G., \& Dweck, C. (1992). Achievement goals and intrinsic motivation: Their relation and their role in adaptive motivation. Motivation and Emotion, 16(3), 231-247. http://dx.doi.org/10.1007/BF00991653

Hidi, S. (2000). An Interest Researcher's Perspective: The Effects of Extrinsic and Intrinsic Factors on Motivation. In C. Sansone \& J. M. Harackiewicz (Eds.), Intrinsic and Extrinsic Motivation: The Search for Optimal Motivation and Performance (pp. 309-339). San Diego, CA, US: Academic Press. http://dx.doi.org/10.1016/B978012619070-0/50033-7

Kyriacou, C., \& Benmansour, N. (1997). Motivation and Learning Preferences of High School Students Learning English as a Foreign Language in Morocco. Mediterranean Journal of Educational Studies, 2(1), 79-86.

Levesque, R. R. (2012). Intrinsic and Extrinsic Motivation. In R. R. Levesque (Ed.), Encyclopedia of Adolescence (pp. 1478-1479): Springer US. http://dx.doi. org/10.1007/978-1-4419-1695-2_639

Lin, Y.-G., McKeachie, W. J., \& Kim, Y. C. (2003). College 
Student Intrinsic and/or Extrinsic Motivation and Learning. Learning and Individual Differences, 13(3), 251258. http://dx.doi.org/10.1016/S1041-6080(02)00092-4

Nawaz, H., Amin, M., \& Tatla, I. A. (2015). Factors Affecting Students' Motivation Level to Learn English as a Second Language in the Pakistani University Context. Journal of Research \& Reflections in Education (JRRE), 9(2).

Ngo, H., Spooner-Lane, R., \& Mergler, A. (2017). A comparison of motivation to learn English between English major and non-English major students in a Vietnamese university. Innovation in Language Learning and Teaching, 11(2), 188-202. http://dx.doi.org/10.1080/17501229 .2015 .1094076

Omari, O., Bourekkadi, S., Slimani, K., Khoulji, S., \& Kerkeb, M. L. (2017). Investigating Undergraduate Students' Attitudes Towards English Mobile Learning. 2017, 5(4). http://dx.doi.org/10.14738/tmlai.54.3210

Park, Y. (2011). How Motivational Constructs Interact to Predict Elementary Students' Reading Performance: Examples From Attitudes and Self-Concept in Reading. Learning and Individual Differences, 21(4), 347-358. http://dx.doi.org/10.1016/j.lindif.2011.02.009

Pintrich, P. R., \& Schunk, D. H. (1996). Motivation in education: Theory, research, and applications. Englewood Cliffs, NJ: Prentice Hall.

Pintrich, P. R., \& Zusho, A. (2007). Student Motivation and Self-Regulated Learning in the College Classroom. In R. P. Perry \& J. C. Smart (Eds.), The Scholarship of Teaching and Learning in Higher Education: An Evidence-Based Perspective (pp. 731-810): Springer Netherlands. http://dx.doi.org/10.1007/1-4020-5742-3_16

Reeve, J. (2012). A Self-determination Theory Perspective on Student Engagement. In S. L. Christenson, A. L. Reschly \& C. Wylie (Eds.), Handbook of Research on Student Engagement (pp. 149-172). Seoul, Korea: Springer US. http://dx.doi.org/10.1007/978-1-4614-2018-7_7

Rifai, N. A. (2010). Attitude, motivation, and difficulties involved in learning the English language and factors that affect motivation in learning it. Procedia - Social and Behavioral Sciences, 2(2), 5216-5227. http://dx.doi. org/10.1016/j.sbspro.2010.03.849

Ryan, R. M., \& Deci, E. L. (2000a). Intrinsic and Extrinsic Motivations: Classic Definitions and New Directions. Contemporary Educational Psychology, 25(1), 54-67. http://dx.doi.org/10.1006/ceps.1999.1020

Ryan, R. M., \& Deci, E. L. (2000b). When Rewards Compete with Nature: The Undermining of Intrinsic Motiva- tion and Self-Regulation. In C. Sansone \& J. M. Harackiewicz (Eds.), Intrinsic and Extrinsic Motivation: The Search for Optimal Motivation and Performance (pp. 13-54). San Diego: Academic Press. http://dx.doi. org/10.1016/B978-012619070-0/50024-6

Sansone, C., \& Harackiewicz, J. M. (2000). Controversies and New Directions-Is it Déjà Vu All Over Again? In C. Sansone \& J. M. Harackiewicz (Eds.), Intrinsic and Extrinsic Motivation: The Search for Optimal Motivation and Performance (pp. 443-453). San Diego, CA, US: Academic Press. http://dx.doi.org/10.1016/B978012619070-0/50037-4

Sansone, C., \& Smith, J. L. (2000). Interest and Self-Regulation: The Relation between Having To and Wanting To. In C. Sansone \& J. M. Harackiewicz (Eds.), Intrinsic and Extrinsic Motivation-The search for Optimal Motivation and Performance (pp. 341-372). San Diego, CA, US: Academic Press.

Smirkou, A. (2015). Moroccan Female Rural Students' Attitudes towards Learning English. Arab World English Journal, 6(4), 291-305.

Thompson, A. S., \& Erdil-Moody, Z. (2016). Operationalizing multilingualism: language learning motivation in Turkey. International Journal of Bilingual Education and Bilingualism, 19(3), 314-331. http://dx.doi.org/10. 1080/13670050.2014.985631

Vallerand, R. J. (2007). Intrinsic and extrinsic motivation in sport and physical activity: A review and look at the future. In G. Tenenbaum \& R. Eklund (Eds.), Handbook of sport psychology ( $3^{\text {rd }}$ ed., pp. 59-83). New Jersey: John Wiley \& Sons. Retrieved from http://books.google.com.

Vallerand, R. J., Pelletier, L. G., Blais, M. R., Briere, N. M., Senecal, C., \& Vallieres, E. F. (1992). The Academic Motivation Scale: A Measure of Intrinsic, Extrinsic, and Amotivation in Education. Educational and Psychological Measurement, 52(4), 1003-1017. http://dx.doi. org/10.1177/0013164492052004025

Wagner, D. A., Spratt, J. E., \& Ezzaki, A. (2008). Does learning to read in a second language always put the child at a disadvantage? Some counterevidence from Morocco. Applied Psycholinguistics, 10(1), 31-48. http://dx.doi. org/10.1017/S0142716400008407

Walker, C. O., Greene, B. A., \& Mansell, R. A. (2006). Identification with academics, intrinsic/extrinsic motivation, and self-efficacy as predictors of cognitive engagement. Learning and Individual Differences, 16(1), 1-12. http:// dx.doi.org/10.1016/j.lindif.2005.06.004 